2002 IEEE Intemational Symposium on Computer

Aided Control System Design Procoedings

Septernber 18-20, 2002 • Glasgow, Scotland, U.K.

\title{
CORAL off-line: AN OBJECT-ORIENTED TOOL FOR OPTIMAL CONTROL OF SEWER NETWORKS
}

\author{
J. Figueras ${ }^{\star *}$, G. Cembrano ${ }^{\#}$, V. Puig ${ }^{\star}$ J. Quevedo ${ }^{*}$, M. Salamero ${ }^{\circ}$ J. Marti \\ "Dept. ESAII, Universitat Politècnica de Catalunya \\ Rambla Sant Nebridi 10, 08222 Terrassa (SPAIN) \\ "Instituto de Robótica e Informática Industrial, IRI (UPC-CSIC) \\ Parc Tecnològic de Barcelona, Edifici U, C/Llorens $i$ Artigas 4-6, 08028 Barcelona (SPAIN) \\ 'Clavagueram de Barcelona S.A. \\ C/Acer 16, 08038 Barcelona (SPAIN) \\ Tel. +34937398621, Fax. +34937398628 \\ E-mail: \{jaumef,vpuig, joseba\}@esaii.upc.es, gcembrano@iri.upc.es, \{msalamero,joaquim\}@clabsa.es
}

\begin{abstract}
This paper describes a tool to aid in the analysis and design of combined sewer networks. Complex drainage systems include actuators, like flow-diversion gates and detention tanks, which should be optimally controlled in order to minimize flooding and combined sewer overflow (CSO), through these optimisations volume to waste water treatment plants (WWTP) is maximised. CORAL is a tool able to model a combined sewer network, simulate rain events, calculate actuators optimal policies reproduce past rain events and calculate different balances for all model elements.
\end{abstract}

Keywords: Urban drainage, Predictive control, Optimal Control, Multi-objective optimisation, Modelling, Simulation, Code generation.

\section{INTRODUCTION}

Nowadays, the concern of society with sustainable development arises. As described in [1] and [2] water management in urban areas is one of the main issues. Water management includes not only water supply but also the disposal of effluents to the receiving environment.

Urban drainage systems are in charge of carrying urban wastewater and rainwater to one or more terminal points, where it is treated or released to the receiving environment. Combined sewer networks carry rain- and wastewater together. In many cities where the conurbation has been growing fast and stormy rains are frequent, the existing combined sewer systems are unable to manage all the water to the treatment plant. Because of this, many problems happens: flooding certain areas of the city and combined sewer overflow (CSO) which release water to the receiving -environment.
Complex urban drainage systems attempt to solve these problems in two ways. First of all, it requires infrastructure, i.e. construction of detention tanks, flow-diversion gates, sluice gates, pumping station, etc. Secondly, it requires the installation of telemetry and supervisory control system. The telemetry system includes rain-gauges, flow or level meters (limnimeters) and quality meters distributed in main sewers and critical points of the network. The supervisory control system includes not only the controller command, but also the computation on control strategies to be applied in a complex sewerage system. In order to optimise the system performance.

Some of the desirable features for the control system are: model simplicity (in order to reduce computational costs and calculate a global optimum), model parameters calibration, user configurable reports and standard database connection via SQL, sensor fault detection and recovery and SCADA system communication. Commercial packages for sewerage simulation and control such as Mouse, ICPR and NetworkX. which use numeric differential equation integration and very detailed geographic and hydraulic information are more useful in design and operations planning but do not serve the purpose of fast strategy computation in a large network. Therefore the development of a tool was decided.

This paper discusses CORAL off-line, a new tool for sewerage network modelling, simulation and optimal strategy computation, which has been demonstrated in a test catchment of the Barcelona sewer network. This tool has been designed to suit a specific purpose: perform a global optimal control of sewer networks. In order to achieve environmental or social management goals such as flood and pollution-discharge reduction. Section 2 describes the model, Section 3 discusses the software design and Section 4 focuses only on the model manager. Section 5 explains how the rain events are simulated and section 6 how are 
reproduced. In section 7 a real case study of the Barcelona sewer network is presented. Finally, sections 8 and 9 conclude and presents the future work to be developed.

\section{OPERATIONAL MODEL}

An operational model of an urban drainage system is a set of equations which provide a fast approximate evaluation of the hydraulic variables of the network and its response to control actions at the gates. This type of model is useful for the computation of optimal strategies, because it makes it possible to evaluate a large number of control actions in a short computation time. This type of model is usually known as a "conceptual" or "transfer function" model [3] and [4] it is also known as virtual-reservoir model [5].

The sewage network is modelled through a simplified graph relating the main sewers and set of virtual and real reservoirs. A virtual reservoir is an aggregation of a catchment of the sewage network which approximates the hydraulics of rain, runoff and sewage water retention thereof. The hydraulics of virtual reservoirs are linearised so that, in discrete time:

$$
x^{k+1}=f\left(x^{k}, u^{k}, w^{k}\right)
$$

$\mathrm{Eq} 1$

where:

u represents a vector of control variables related to gate positioning (e.g. flow through the gate), $x$ is a vector of observable states: stored volumes in reservoirs (real and virtual) and flows (or water levels) in main sewers, $w$ is a disturbance vector containing rainfall intensities in the different catchments, $f$ is a linear function expressing the mass balance of rain intake, sewer flow and reservoir volumes in the network. Its structure depends on the topology of the network and its parameters must be estimated using real data from the sensors installed. Finally superindexes $\mathrm{k}$ indicate time intervals.

\section{OBJECT-ORIENTED SOFTWARE DESIGN}

CORAL, Spanish acronym for Sewer Networks Optimal Control, is comprised of four off-line modules. A model manager, a rain event simulator, a rain event reproducer and a balance generator. All four modules interact with the model data structure and/or the CORAL data base as shown in figure 1 .

As CORAL's model data structure is modelling real elements and all these elements are highly typified and classified into hierarchies, an object-oriented design has been chosen in order to use object-oriented paradigm properties like polymorphism, inheritance, etc. Objectoriented paradigm was also chosen due to its high maintainability and flexibility for introducing new elements in the object data model.

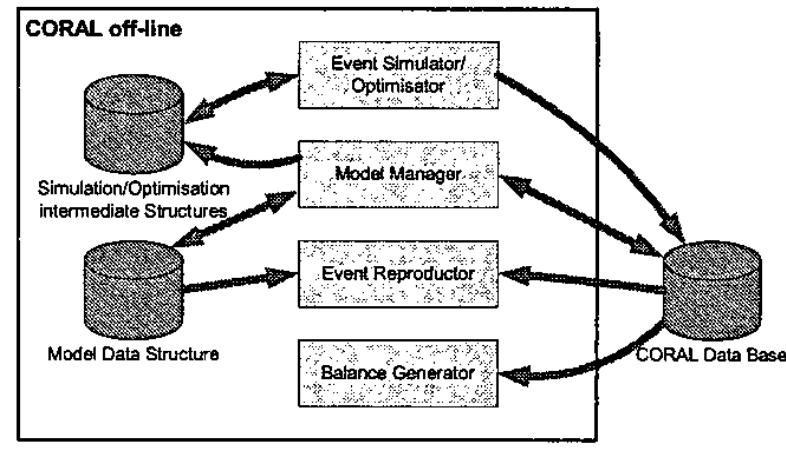

Figure 1: CORAL off-line system architecture

CORAL's OMT object data model is presented in figure 2 . The root of this model hierarchy begins with Hydraulic Element who maintains common data such as identifiers, inputs, outputs, and drawing options and procedures.

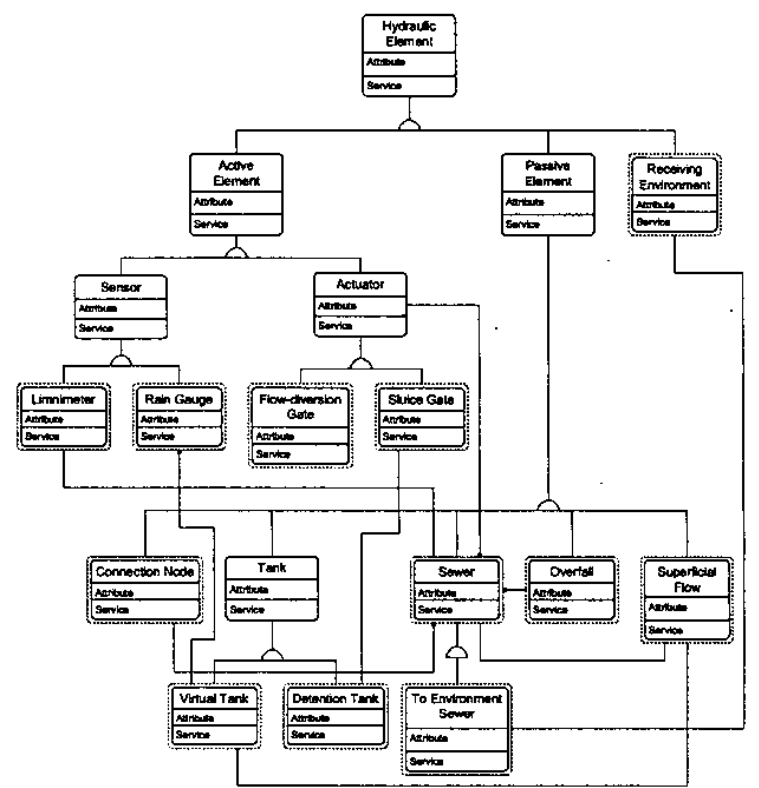

Figure 2: CORAL object data model

Hydraulic Element has three subclasses, Active Element, Passive Element and Receiving Environment. Active elements are those who manage input or output data, so this class hierarchy ends up in sensors like, rain gauges or limnimeters, and in actuators like, flow-diversion gates and sluice gates. On the other hand passive elements model structural dependencies. This hierarchy ends up in sewers, tanks, connections, overflow sites and runoffs. Finally the receiving environment object is a special class in charge of accumulating outputs of the entire model.

Figure 2 also shows instance-to-instance associations which bind different object instances preventing structural model 
inconsistency. This kind of associations ensure that a Detention Tank has an associated Sluice Gate or that a To Environment Sewer ends in a Receiving Environment.

\section{MODEL MANAGER}

The model manager is a graphical user interface that manages the construction of an hydraulic model. It is also in charge of the model validation and the optimiser equation generation.

\subsection{Graphical user interface}

The graphical user interface has been build using Microsoft MFC in Visual $\mathrm{C}++$ programming environment. So this module binds the object data model with MFCs. It builds an hydraulic model by including a polymorphical list of Hydraulic Elements in the document/view structure.

An example hydraulic model is shown in figure 3 . This GUI implements typical mouse event response such as element drag\&drop, element double-click configuration, etc. To implement this features each element interfaces its own polymorphic drawing, selection, deselection and configuration routines virtually defined in Hydraulic Element simplifying code complexity.

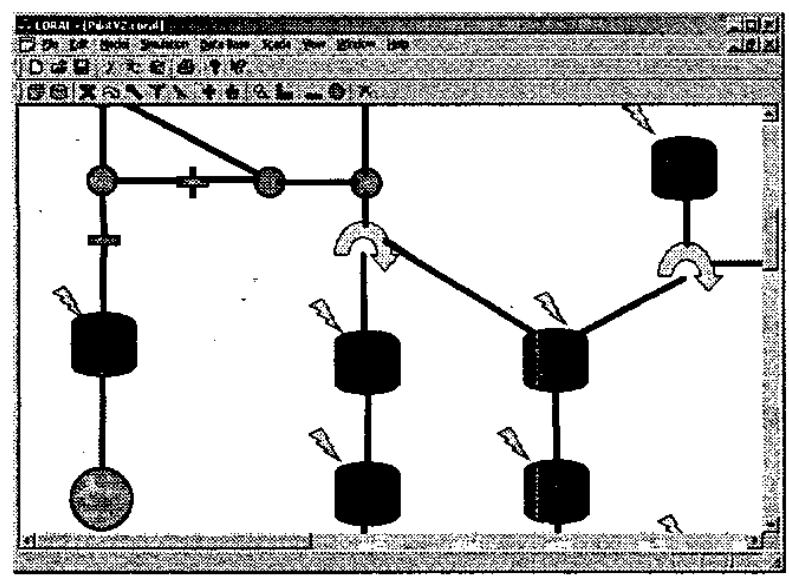

Figure 3: CORAL off-line GUI

-As mentioned earlier, each element provides his configuration routines. When a user double-clicks on an element the GUI calls a polymorphic modal dialog box defined in Hydraulic Element and implemented virtually in each subclass.

\subsection{Model validation}

During the construction of a complex model errors may be introduced. Not only individual errors, a correctly configured single element may cause inconsistency and malfunction of the whole hydraulic model. That is why a model validation phase must be implemented. Figure 5 illustrates the validation and error detection phase output.

A non exhaustive list of errors detected by CORAL off-line is: element redefinition, inexistent element references, input/output existence and type, sensor association, parameter incongruence, etc.

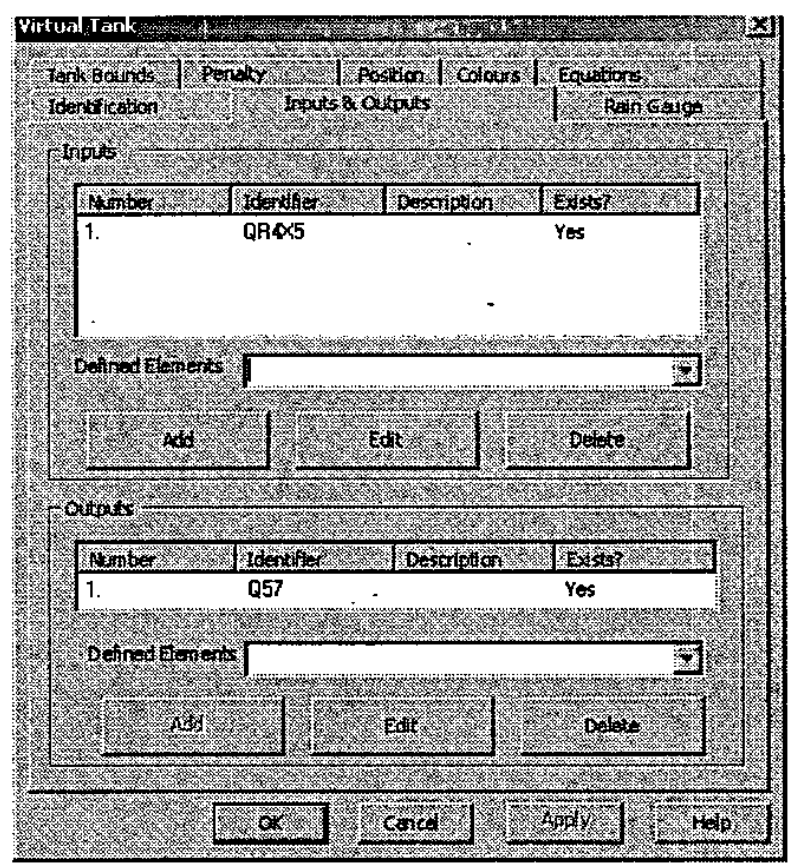

Figure 4: Different configuration options depending on selected element

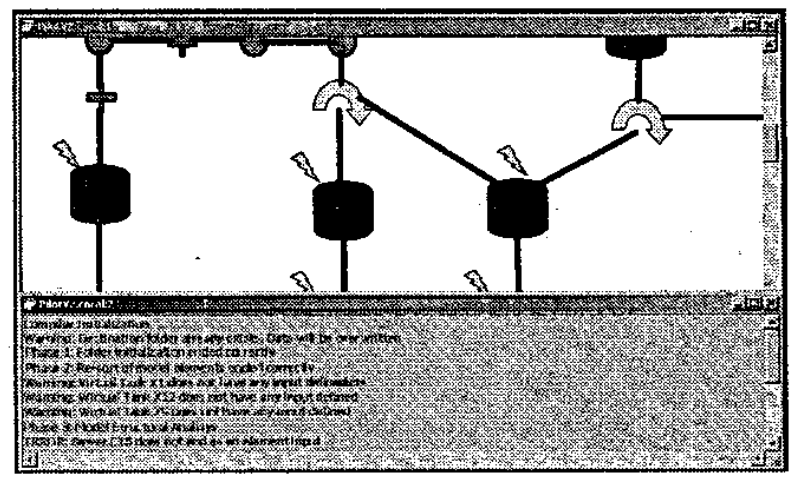

Figure 5: Error detection phase output

\subsection{Optimiser equation generation}

Finally the model manager is also responsible of generating error-free equations that will be used by the optimiser program. The model manager must accept different configuration parameters. The configuration of the 
optimiser cost function for global model parameters, such as which receiving environment has to be penalised, selection of how the superficial flows must be computed or how to deal with the regulated water in the detention tanks. Model manager also permits the user to define the equation files to be generated. Figure 6 shows the equations: configuration options.

The optimiser used is GAMS, so the file format complaints with GAMS syntax [7]. Figure 7 presents the main file which will start the simulation and optimisation process.

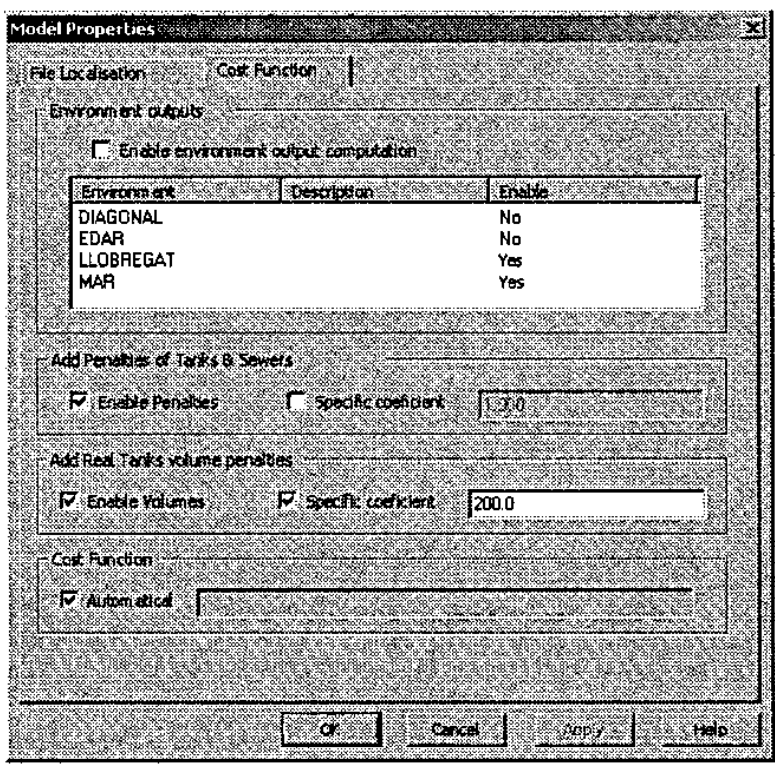

Figure 6: Equation generation configuration

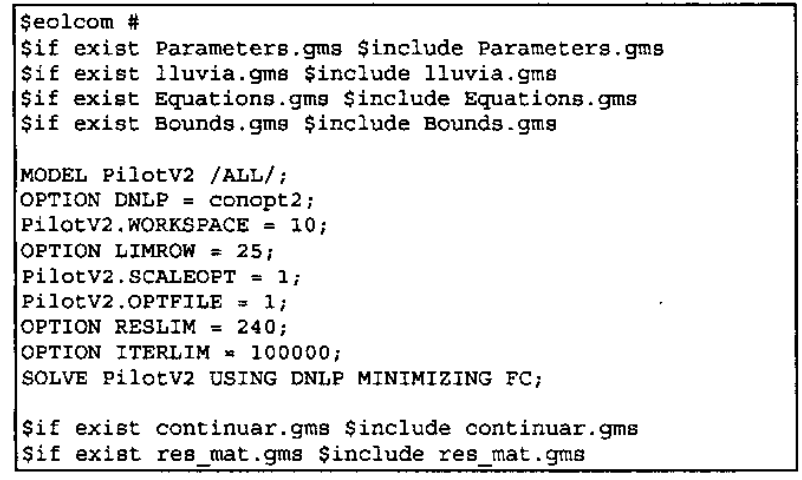

Figure 7: Main file automatically generated

\section{EVENT SIMULATOR}

The event simulator simulates a hydraulic model with a certain rain. It must perform the following tasks: reading the rain intensity data from the CORAL data base, generating rain equations according to rain and model data, launching GAMS to optimise the control variables and compute model dynamics, collecting GAMS output and generating the model equations initial point for the next simulation step.

There are different configurable simulation options. CORAL simulation option manage file localisation and simulation parameters, like, simulation length, initial rain time, rain prediction model, desired output (complete output or summarised output). Once the simulation has finished and depending on output configuration CORAL generates a report including all element values for each time interval that can be read with any standard analysis tool like Excel or Matlab. CORAL also generates an error report indicating for each time interval how the optimiser has solved the problem, i.e. whether it has reached a global optimum, number of non optimal variables, infeasible solutions and optimiser error condition. Additionally the simulation results can be written to CORAL's data base for later reproduction.

\section{EVENT REPRODUCER}

The event reproducer reads data from an existing simulation and animates the model in order to show a pseudo-dynamic evolution of the sewer network. Figure 8 is an example window of an event in reproduction mode. Note that levels in each tank are indicated by their coloured level that can be configured for each tank. In fact all active and passive elements can be animated but the end user can set up which elements will be animated

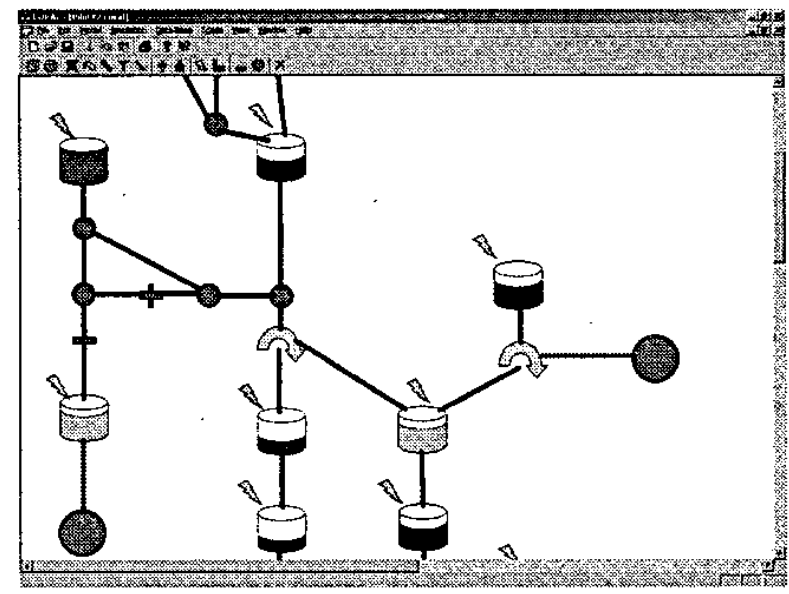

Figure 8: Event reproducer window

CORAL off-line allows different reproduction parameters, such as information depth, elements to be animated, colours used to display different levels, animation speed factor, etc. Reproduction is not used to analyse the network but it makes it possible to synthesise globally all network information in one synoptic window. 


\section{CASE STUDY: BARCELONA TEST CATCHMENT}

Clavegueram de Barcelona, S.A. (CLABSA) is the company in charge of the sewer system management in Barcelona. The Barcelona urban drainage network contains approximately 1600 kilometres of sewers carrying a daily volume of some $300 \mathrm{~m}^{3}$ wastewater in dry weather and the rainwater an average precipitation of $600 \mathrm{~mm}$ a year. It includes 3 detention tanks (other 3 are under construction, to be inaugurated by 2002) with a total of $273000 \mathrm{~m}^{3}$ capacity and 16 gates are currently in operation. A telemetry network containing 24 rain gauges, more than 100 limnimeters and a few quality sensors connected to a Supervisory Control and Data Acquisition system (SCADA) have been in operation since 1994. Local reactive control of the flow regulation devices in the network has been in use since 1998 .

With the objective of reducing flooding and CSO and in order to take full advantage of the storage capacity of the urban drainage network and the treatment plants, a collaborative project for the implementation of the study of global control in the whole Barcelona network is underway. An off-line prototype of the system has been recently developed and tested. The predictive control set-up used in this prototype has been tested further, in order to assess the validity of the obtained optimal strategies and the influence of the prediction approach on the fulfilment of the control goals.

An important area of Barcelona, shown in figure 9 has been selected as a test site to analyse the results of this work. It is comprised of 11 virtual reservoirs, one real detention tank with its inlet and outlet gates, 18 main sewers, 3 flowdiversion gates and 5 overflow diversion devices modelled in figure 10. It includes the connections to the sea and to the wastewater treatment plant, as well as superficial flows during flooding events.

After the selection area of the benchmark, all the parameters of this model have been estimated with historic data of water level sensors and rain gauges, using the MATLAB System Identification Toolbox.

The optimal control strategies obtained with the abovedescribed system were shown to produce significant improvements on flooding and CSO minimisation, as well as in the use of the treatment plant capacity [6].

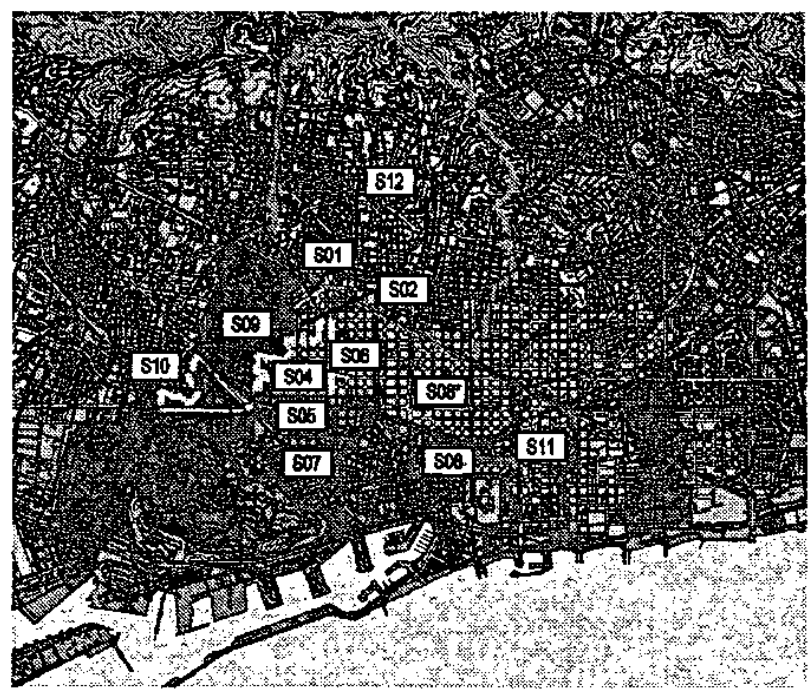

Figure 9: Barcelona test catchment map

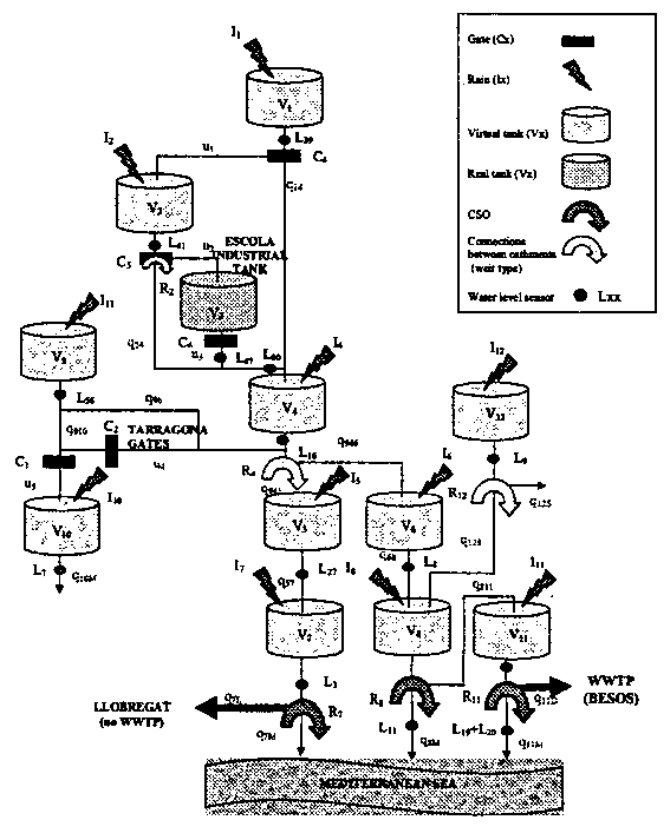

Figure 10: Barcelona test cathment model

As an illustration, figure 11 shows the comparison of the total flooding, CSO and treatment plant volumes in three situations: without a detention tank, with the detention tank but using it as a passive element (inlet and outlet gates open at all times) and with optimal control simulated with real rain using CORAL off-line. The heavy-rain scenario corresponds with an average return period of 4 years and peak return periods of 12 years. In depth results of test simulations can be found at [8] with different rain prediction strategies [9] 


\begin{tabular}{|c|c|c|c|}
\hline \multicolumn{4}{|c|}{ Heavy-Rain Episode (14/09/99) } \\
\hline & $\begin{array}{l}\text { Passive no } \\
\text { tank }\end{array}$ & $\begin{array}{c}\text { Passive with } \\
\text { tank }\end{array}$ & Optimized \\
\hline looding, $\mathrm{m}^{3}$ & 178647 & 138582 & 130293 \\
\hline 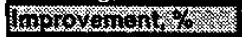 & 2 & 22.43 & 270 \\
\hline Treated Water, $\mathrm{m}^{3}$ & 117375 & 132900 & 134307 \\
\hline moravernom 6 & 2 & 18,25 & 19.48 \\
\hline CSO & 878817 & 867378 & 865509 \\
\hline & & (2) & 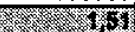 \\
\hline
\end{tabular}

Figure 11: Results with heavy-rain scenario

\section{CONCLUSIONS}

This paper presents a new simulation/optimisation tool, named CORAL off-line, for the analysis, study and control of sewer networks. This tool has been used successfully in collaboration with CLABSA for a test catchment of the Barcelona sewer network. The same tool is being used to model and study the localisation and benefits of retention tanks in collaboration with EMUASA for the Murcia sewer network.

\section{FURTHER WORK}

An on-line extension of CORAL will be implemented also in collaboration with CLABSA to implement the global optimal control of the complete sewer network of Barcelona.

All efforts are now on the on-line implementation of CORAL. An on-line implementation should include the next modules and utilities:

- On-line model parameter estimation.

- On-line sensor and actuator fault detection and data recovery if possible.

- Communications module with SCADA and CORAL.

- Element capabilities extension (SCADA data binding, associated alarms, parameter estimation procedure, data substitution procedure, etc.)

- Balance generation of selected data

- Map-to-background binding.

\section{ACKNOWLEDGEMENTS}

This work has been partly funded by the CICYT (Project COO1999 AX072) Authors J. Quevedo and V. Puig are members of LEA-SICA (Associated European Laboratory on Intelligent Systems and Advanced Control)

The contribution of the CLABSA staff in supplying data and validating the experiments is gratefully acknowledged.

\section{REFERENCES}

[1] Krebs, P and Larsen, A. (1997) "Guiding the Development of Urban Drainage Systems by Sustainability Criteria". Water Science and Technology Vol. 36, No. 8-9 pp 19-24 Elsevier. Great Britain.

[2] Price, R. K. (2000) "Hydroinformatics and Urban Drainage: An Agenda for the 21 ${ }^{\text {st }}$ Century" Journal of Hydroinformatics Vol. 2 No 2 IWA Publishing

[3] Norreys, R and I. Cluckie (1997). "A Novel Approach to Real-Time Modelling of Large Urban Drainage Systems". Water Science and Technology Vol. 36, No.8-9 pp 19-24. Elsevier. Great Britain

[4] Cluckie, I D., Lane, A. and J. Yuan (1999). "Modelling Large Urban Drainage Systems" Real Time Water Science and Technology Vol. 39, No.4 pp 21-28. Elsèvier. Great Britain.

[5] Ballester, J.L., Martí, J. and M. Salamero (1998). "Control de Compuertas de Derivación en la Red de Alcantarillado de Barcelona". Ingeniería del Agua. Vol. 5, No 4, pp. 37-46.

[6] Cembrano, G., Quevedo, Salamero, M., Puig, V., Figueras, J. and J. Martí (2002). "Optimal Control of Urban Drainage Systems". Control Engineering Practice (in press). Elsevier. Great Britan.

[7] GAMS (1997). "The Solver Manuals". GAMS Development Corporation. Washington DC.

[8] Cembrano, G., Figueras, J., Quevedo, J., Puig, V., Salamero, M., Marti, J. (2002) "Global control of the Barcelona sewerage system for environment protection". Proceedings of the 15th IFAC World Congress on Automatic Control.

[9] Toth, E., Brath, A., A. Montanari (2000). "Comparison of short-term rainfall prediction models for real-time flood forecasting" Journal of Hydrology, 239, 132-147. Elsevier. 